A FEW minutes after sunset on Thursday last (23rd) I saw a very fine meteor in the direction E.N.E.

Its course at first appeared southerly, then, bending downwards, it seemed slowly to drop in a direction perpendicular to the horizon, and I lost sight of it behind a clump of trees. Its
light was exceedingly brilliant.

Leyton, Essex, March 27

\section{Books Wanted}

THE only way in which your correspondent of last week, $\mathrm{Mr}$. H. J. Watson, is likely to obtain the volume of the "Annales de Chimie," containing the paper of Braconnot, (not Bracconot, the misprint is Sir John Herschel's), and that of the "Philosophical Transactions" with Dr. Prout's paper, would be to request some second hand scientific bookseller to place them on his list of "desiderata," so that they may be brought under the notice of those who are likely to have duplicates.

Perhaps Mr. Watson is not aware that there is a good abstract of Braconnot's paper, occupying just over six pages in the Quarterly Goumnal of Science, vol. viii. 1820 , and also short abstracts in the Edinburgh Philosophical fournal, No. iv. 1820 , and 'Tulloch's Philosophical Magazine, vol. lv. 1820. It has also been reprinted into some foreign scientific periodicals, a list of which may be seen on reference to the "Royal Society's Catalogue of Scientific Papers," vol. i.

Oxford, March 24

JAs. B. BAILEY

\section{Measurement of Mass and Force}

Professor EVERETT, towards the close of his much-needed and exhaustive letter in NATURE (March 2) on the Measurement of Mass and Force, proposes to supply an undeniable want in Dynamics by coining the word kinit to denote that force which, acting on an avoirdupois pound of matter for a second, generates a velocity of a foot per second. He then adds, "If we substitute gramme for pound and metre for foot, we obtain a different unit which must be called by a different name."

Now one, and perhaps the only, objection to this is that in the face of the rapidly spreading metrical system it seems injudicious and somewhat savouring of retrogression to appropriate the most suitable root at our disposal to designate a force-unit depending upon the pound and foot (the abandonment of which is now only a question of time), while that based on the gramme and metre is sent a begging. I would therefore suggest to Prof. Everett that a kinit (or simply the monosyllabic kin) be defined as that force which, actnng on a gramme of matter for a second, generates a velocity of a metre per second; and then there would follow as a matter of course kiloknn, \&c., suggestively and conveniently denoting either "the amount of force which, acting on a kilogramme, \&c., of matter for a second, generates a velocity of a metre per second," or, "the amount of force which, acting on a gramme of matter for a second, generates a velocity of a kilometre, \&c., per second."

Besides Kinetics and Heat (see Nature, vol. i. p. 606) there is another department of science where a similar want existsless pressing, perhaps, as yet, but felt, nevertheless. This is Electricity. Taking as basis Sir W. Thomson's general definition of unit quantity of frictional electricity (Camb. and Dubl. Mathematical fournal, March, 1848) a particular unit (i.e. a unit dependent upon previously fixed particular units of force and distance) might be chosen, formally defined, and named.

This question of units of measurement and their names appears to me to be anything but trivial. A science, which, by the choice of one good system of units, and the adoption of a susgestive definite and aniform nomenclature, has put its house in order for the proper reception of the powerful chief Mathematicus, has laid the foundations of true and rapid progress.

College Hall, St. Andrews

ThOMAs MUIR

\section{The Earthquake}

A RATHER severe shock of earthquake was experienced in this neighbourhood on Friday, March 17 . The day in question had been remarkably calm, and a heavy suffocating feeling in the atmosphere noticed. About I I. I5 P. M. a somewhat loud rumbling noise was heard as if a heavy waggon was passing over pavement; windows, chandeliers, furniture were violently shaken. Cups and saucers made themselves heard, and beds in some cases were distinctly felt to oscillate and heave like a ship at anchor. Breathing in some cases became difficult, but whether from fright or the oppressive state of the atmosphere does not appear. The vibrations were apparently horizontal, nirl probably in a direction from N. to S., lasting about three or four seconds. Poultry and cage birds showed particular distress by the noise and fluttering which they made. The temperature, which on the previous Tuesday night had fallen as low as $17^{\circ}$, suddenly changred, and the minimum of Friday night was $4 \mathrm{I}^{\circ}$. Saturday morning was remarkably warm; the black bulb thermometer in vacuo reading $92^{\circ}$. The barometer showed no unsteadiness, but had been gradually rising for some days previously. The shocks seems to have been felt from the south of Scotland as far as the north of Derbyshire, much the same account having been received from each locality.

Blencowe, Penrith, March 20

THOMAS FAWCETT

THE earthquake recorded for the night of Friday ( $\mathrm{l} 7 \mathrm{th}$ ) last was felt here about I I P. M., distinct vibration being observed by two members of my household.

In support of the theory that shocks are mainly noted along lines of fault, there is a considerable one within a short distance extending northwards for some miles.

Charles Henky MidDleton

Lingen Vicarage, Presteigne, Herefordshire, March 23

A SLIGHT shock of earthquake was felt and heard in this neighbourhood at about 9.55 on Monday night last, the 2oth instaint.

The duration of the shock was not longer than three seconds; it was accompanied as if by a muffled explosion, followed by a slight rumbling of the earth, and a gradual dying away of the sound, which seemed to be in an easterly direction. The last sensation is obviously not very reliable, as much will depend upon the position in which the hearer was sitting.

\section{Stretton Rectory, Hereford, March 23 \\ The Reality of Species}

HENRY COOPER Key

AMONG the many misconceptions that have arisen in connection with the doctrines of evolution appears to be one that species have no real existence. In a recent review (appearing in one of the best London papers) of Mr. Mivart's work, this mistake is strongly expressed, the writer appearing to entertain a profound contempt for anyone who still retains the foolish notion that there is any such thing as a species in nature. Every working naturalist knows well that most assuredly species do exist, and that in the most positive manner, not being conventional merely, but separated from one another in nature by distinct and real characters.

Fortunately for the doctrine of natural selection, it does not in the least question this fact, for did it so, it would be disposed of at once by pointing to a red admiral and tortoiseshell butterfy flitting side by side. It cannot be too distinctly insis'ed on that natural selection opposes no barrier whatever to the reception of the idea of distinct and separate species. That which it has destroyed is the notion of the constancy of species if the idea of time be set on one side. To argue that species have at the present day no separate existence because they had formerly a common origin, is a foolish confusion. The separate existence of a full-grown and mature animal is not questioned, because at one period it was a bud closely connected with its parent. In point of fact the question of species is really very similar to that of individuality, viewed as a question of origin, the individual and the species are both untenable ideas; but viewed at any une moment, both individual and species are among the most prominent and unduubted facts of our experience. Equally futile is it to argue that species have no existence, because we cannot exactly define what we mean by a species. It is well known that all the efforts of biologists have hitherto failed to produce a satisfactory definition of life. Are we, then, to conclude there is no such thing as a living animal?

The evolutionist contemplates throughout the universe a power underlying all things, indestructible and infinite, most various in its manifestations, always changing and always shifting, but steadily in a given direction, not revealed to man as a separate existence, but known only by its changes and movements, and veiled under the form of matter. Side by side with this universal and unknowable force he sees an opposing power, a tendency in things and matter to be always as they have been, a tendency which the restless force has ever to overcome; but as soon as this has gained its victory, again is it subject to the grasp of its ignoble foe; the struggle, though becoming ever more and more one of detail, is no spasmodic one, though more revealed to us 